\title{
How Much "Group" is there in Online Group Work?
}

\author{
Susan Lowes, Ph.D. \\ Institute for Learning Technologies \\ Teachers College/Columbia University
}

\begin{abstract}
The ability to work in groups across time and space has become a frequent requirement for the workplace and is becoming increasingly more common in higher education, but there is a surprising lack of research on how online groups work. This study applies analytical approaches used in studies of face-to-face classroom "talk" to multiple groups in two asynchronous online high school courses. We investigated two activities focused on group problem-solving styles - one for deciding how to work as a group, and a second for responding to the content of the assignment. We found successful groups to have benefited from directive leadership, and the division of labor amongst most groups to be in parallel rather than collaborative.
\end{abstract}

\section{INTRODUCTION}

"I liked the course altogether, just remove the group activity things, they do not help with learning and take a lot more time than just doing it by yourself."

"No group projects. At all. Ever."

--Comments from high school students in an online course

There are three types of interaction in an online course: teacher-student, student-content, and studentstudent. Cohort-paced virtual classrooms were built, first in higher education and then in some K-12 virtual schools, in the belief that student-student interactions are an essential component of online learning. This belief was in turn based on constructivist theories that hold that content is best learned in discussion with others. It was built into the standards for K-12 online courses and online teaching, including those developed by the International Association for K-12 Online Learning (iNACOL) [1, 2], which refer repeatedly to learning through group collaboration. For example, in the most recent version of the standards for courses, one of the criteria for a successful course is that it "provides multiple opportunities for students to be actively engaged in the content that includes meaningful and authentic learning experiences such as collaborative learning groups...” [1, p. 10]. Similarly, one of the standards for teachers is that "The online teacher plans, designs, and incorporates strategies to encourage active learning, application, interaction, participation, and collaboration in the online environment” [2, p. 6]; of the nine elements in that standard, two refer specifically to group work.

Although the ability to work in groups across time and space has become an increasingly frequent requirement for the corporate workplace (see, for example, the many references listed by the Partnership for $21^{\text {st }}$ Century Skills) and is increasingly common in higher education, there is a surprising lack of 
research on how groups work online. There are a few suggestive studies on virtual teams in business [see particularly $3,4,5,6$ ] and a few studies in higher education [see review by 7 ; for examples, see $8,9,10$ ], but nothing at all at the secondary level.

The goal of this research was to begin to fill this gap by exploring how online groups of high school students in fully online asynchronous cohort-paced (rather than self-paced) courses formulate, develop, and accomplish group projects in order to understand what team problem-solving and group interaction look like in such courses. It addresses the following specific questions:

- How much do students collaborate in a group project in an online course?

- What does this collaboration look like?

- Is the type and extent of collaboration linked to the success of the final product? If so, how?

\section{CLASSROOM “TALK”}

While there is only a limited amount of research on group work in online courses, there is a large and sophisticated body of research on classroom "talk" in face-to-face groups. Since it is often helpful in thinking about the specific affordances and constraints of online classrooms to compare them to face-toface classrooms, this research adapted insights from studies of face-to-face group work to the analysis of online group work, particularly the research done by Neil Mercer and his colleagues with elementary students in England [for example, 11, 12, 13, and 14] and by Brigid Barron with middle school students in the United States $[15,16]$.

Many differences exist between group work in an asynchronous online environment and group work in traditional face-to-face environments. The most obvious is that "talk" is written text. In the context of the group projects discussed here, "talk" took the form of discussion forum posts in each group's private discussion area and contributions to a final document or presentation. Other differences were that students could not see each other, which meant discussions lacked physical cues-e.g., gestures and facial expressions were not part of the students' exchanges. In addition, talk is asynchronous, which means no interruptions or violations of turn-taking and therefore few fragments, but also the possibility of overlapping utterances and responses ranging anywhere from a few minutes to days apart. The wellknown affordances of online learning — having the time to reflect before "talking" (i.e., posting)—are therefore counterbalanced by the constraints of time and distance.

\section{THE SETTING}

The setting is two courses offered by an online course provider that offers supplementary online courses to upper level high school students from around the world. As a result, the students are in different time zones-an important contextual factor. The courses were asynchronous and cohort-paced on a weekly schedule. They included many different types of activities but had a heavy emphasis on the use of discussion forums and included at least one group project each semester. The courses received high ratings. However, as indicated by the quotes on the first page, taken from end-of-year surveys, the group work aspect did not.

The research was conducted in two phases. In the first phase-which examined styles of group collaboration-examples were taken from a four-week group project in a year-long Economics course, as well as a three-week group project in a year-long Psychology course. These two courses were chosen from among the provider's offerings because their group projects were held up as good examples by the provider and by the course teachers. In the case of the Economics course, there were five groups with four to five students per group. In the case of the Psychology course, there were seven groups with three to six 
students per group. In the second phase of the study—-which focused on interactions within groups—data was drawn from the Psychology course only.

In the Economics course, the group project occurred at the end of a unit on supply, demand, and equilibrium. The unit consisted of three activities, each focusing on a different aspect of the same topic. Within each activity, students were asked to complete five sub-questions and one summative question. Students were instructed to work together on all activities and formulate answers to the questionsincluding the final summative question-using a private discussion forum limited to members of their group. Responses were then to be completed using Microsoft Word. In the Psychology course, the assignment asked students to brainstorm social and cultural factors influencing memory, research the topic, and jointly create and publish a report using the private discussion forums for brainstorming. For the final product, students were instructed to use Google Presentations.

\section{ANALYTIC APPROACH}

\section{A. Conditions for collaboration}

In an early article, Neil Mercer [11] argued that not all classroom talk is equally good for solving problems and advancing understanding. He proposed two conditions for "good" talk:

First, it is talk in which partners present ideas as clearly and explicitly as necessary for them to become shared and jointly evaluated. Second, it is talk in which partners reason togetherproblems are jointly analysed, possible explanations are compared, joint decisions are reached. From an observer's point of view, their reasoning is visible in the talk [11, p. 363; italics in the original].

He then suggested that three conditions must be met for this kind of talk to happen: (1) talk must be necessary to complete the task, (2) the activity must be designed to encourage cooperation, and (3) the participants must have a shared understanding of the purpose of the activity [11, p. 363].

In theory, for these two courses the first condition was met, since all students were required to participate. In practice, it was not. In fact, the first and perhaps most surprising finding was that in all but three of the 12 groups studied, at least one group member never showed up and in most of the other groups additional members absented themselves for long periods of time-only to arrive after the work had been completed, full of apologies (e.g., "I'm so sorry that I am so extremely late."). This created difficulties for the active group members, who had to decide whether they wanted to wait or move ahead without the absent member. We will return to this issue below.

The third condition was also met: participants did have a shared understanding of the activity. It was the second condition-whether the activity was designed to encourage cooperation - that turned out to be a central one. This is a particular issue in the online environment, where the design of the problem has been fixed by the course designer and cannot be modified on the fly, as can be done in a face-to-face classroom. In both the Psychology and Economics courses, the instructional designers believed they had created highly collaborative projects. In face-to-face classrooms these projects may well have worked well as such. In the online environment, however, they seldom did.

\section{B. Styles of collaboration}

In an early article on styles of group collaborative problem solving in face-to-face classrooms, Brigid Barron wrote that her aim was to "describe the types of interactions that contribute to or inhibit coordination" in problem-solving groups [15, p. 404]. In her analysis of in-class group work, she used Forman and Cazden's [17] three styles of working together: 
- Parallel interactions, where the group members exchange comments about the task but do not monitor each other or share thinking. In the present context, this would mean that there would be no interchange of ideas, with the final product a cumulation of individual contributions.

- Associative interactions, where the group members share some information about the task but do not coordinate roles. In the present context, there might be some monitoring of others' contributions, some interchange of ideas, but the final product would still be a cumulation of individual contributions.

- Cooperative interactions, where group members constantly monitor each other's work and play complementary roles in completing problems. In the present context, there would be a robust interchange of ideas and the students would jointly create the final product.

Mercer's categories of exploratory, cumulative, and disputational talk [13] could also have been useful here but Barron's categories seemed more applicable to analyzing a project with a final product. Another fruitful avenue would have been an adaptation of Anderson's "argument stratagems" [see, for example, 19]. It is important to note that all of these look at the evolution of the discussion over time.

In a later article, Barron argued that successful and unsuccessful groups differed in how they responded to proposed problem solutions. She outlined three possible responses to initial proposals [16, p. 323]:

- Accept

- Discuss

- Reject or ignore

In her research, Barron found that more successful groups had higher proportions of Accept and Discuss while less successful groups had higher proportions of Reject or ignore.

Barron's work seemed a potentially fruitful starting point for analyzing online group projects. We therefore took the discussion posts (the online equivalent of transcripts of conversation) and created discourse maps [18] based on Barron's coding scheme in order to see how each post moved the project forward or, as sometimes happened, stopped it in its tracks. The focus was thus on the content of each post individually, on the flow of posts over time, and on the relationship of one post to the next.

The discourse maps immediately made it clear that the first and second posts were particularly important in terms of whether the group got off on the right track and completed the tasks set them. In order to capture this, Barron's scheme was expanded by adding three styles to the first, or initiating, posts and by adding one style to the follow-up posts. The result was the following coding scheme:

Initial posts

- Telling

- Telling with a question (i.e., asking for consent)

- Asking

Responding posts

- Accepting

- Asking for clarification

- Discussing

- Rejecting

\section{THE RESULTS}




\section{A. Importance of initial posts}

The examples below, from both Economics and Psychology, show how these styles of collaboration played out in different groups. They not only illustrate the importance of the initial and responding posts in setting the group up for subsequent interactions, but show how much time is spent getting organizedeither discussing organizational issues or waiting for other members of the group to show up-and how little is spent actually working together on the project itself. They also show that the groups that began with a directive style (Telling), followed by an agreement (Accepting) were more likely to complete their projects than groups that began with a discussion (Telling with a question, or Asking). The problemsolving style for these initial interactions was often cooperative (at least for those who took part). However, no matter what problem-solving style the group relied on to get organized, the interaction about the content was in all but one case entirely parallel. In other words, in the online environment there are actually two sets of activities, each of which demands a different problem-solving style-one problemsolving style for deciding how to work together as a group and a second for responding to the content of the assignment.

\section{Example \#1: Economics}

Economics had five groups, called here Econ-A, Econ-B, etc.

Group Econ-A had five members. One began:

FIRST POST: "There's a total of fifteen question here and five of us. I'll start off by doing the first three. Whoever posts next, do the second three, and so on.” (Telling)

RESPONSE: “Hey everyone, here are my answers to \#4, 5.” (Accepting)

The two other members of the group responded to the remaining questions. The first poster then submitted the assignment.

This group followed the same format for the next two sections of the assignment as well, with the same first poster again suggesting how the work be split (Telling) and the others following along (Accepting). At no point were different members' contributions reviewed or edited by any of the other members. Thus, the group's problem-solving style took the form of parallel interaction.

In Group Econ-B, with four members, one member took the lead as well, but did so more tentatively:

FIRST POST: "Basically, there are three assignments and four of us.... So maybe each of us could do one assignment [she then outlines the assignments]. Sorry to be so horribly bossy, I just want to get this done! ...” (Telling with a question)

This post illustrates another aspect of online group work, which is the tendency for women to apologize for being organizers.

The student then somewhat undermines her own suggestion by opening it up for discussion:

FIRST POST [continued]: “... As far as me, I'm fine with pretty much any of these [assignments] except number two (I won’t have lots of time tomorrow and on Monday I have a full class schedule). So please pick the slots."

Two other members of the group then pick their assignments, but one never shows up. The first poster then makes a suggestion, but again somewhat tentatively:

FIRST POSTER: “I'm trying to think of the best way that we can do this. [She then suggests a complicated division of the work.] It's not a perfect system by any means, but it's all I can think of. Let me know what you think ASAP as I'll probably be trying to finish up with this by the end of the school day. So...does this work?” (Telling with a question) 
She also takes the lead on the next assignment by announcing that she did the first problem, plans to do the next and asks who would like to do the rest, accompanying her suggestions with additional apologies for being bossy.

Despite the tentative nature of the lead member's suggestions, the other two fall in line and the three get the project finished. This again is an example of parallel interaction, since there was no communication among group members about the content of the answers.

Group Econ-C, which had three members, struggled from the beginning. This is the entire conversation for the first five days:

FIRST POST: "So how are we going to do this? We have to split the work equally because I'm sure all of you, like me, have a lot on their plate already." (Asking)

RESPONSE: "I think at this point we need an outside method of communication. This doesn't seem to be very efficient.” (Asking)

FIRST POSTER: “Umm, ok, what do you suggest?” (Asking)

At this point, the teacher steps in and suggests that they stop waiting for each other and start the work. The first poster then takes the lead:

FIRST POSTER: "Since this is a group assignment, we are going to split each assignment so that we all contribute equally (more or less). I looked at each assignment and have split each one into equalish shares.” (Telling)

He then does his assignment, a female student apologizes that she was traveling, submits her piece a day late, and then disappears again. With no interaction about the content itself, this was another example of parallel interaction.

Group Econ-D also has a missing group member but even less luck managing the situation. In this case, one team member proposes a division of labor (Telling) and a second group member agrees (Accepting) but the third group member never shows up. This group keeps waiting for the missing member to do a piece and ends up only submitting a partial assignment. Although the group members discuss how to organize themselves, at no point do they discuss the content of the assignment.

For both Group Econ-C and Group Econ-D, the teacher chimes in toward the end and congratulates each group for great group work.

In fact, there was only one group in the Economics course where there was any interaction about the assignment itself. Group Econ-E had four members. The conversation began as follows:

FIRST POST: “Alright everyone, we have until the $11^{\text {th }}$ to get this done. Therefore, we need to start now. I have answered the questions. If you desire, critique these answers in a respectful fashion.” (Telling)

This student has done the entire first part of the assignment and posted it for others in the group to respond to. He is queried by one of the group members about some of his wording (Asking for clarification) and they go back and forth in a fairly constructive manner (Discussing). When the other two group members do not show up, the first poster again takes the lead:

FIRST POSTER: "I initially hoped that the rest of our team would pull our weight but at this point it would be much easier if us two did it. Anyway, I think it would be best if you do the next one and I do the last one. Let me know what you think.” (Telling with a question)

His partner agrees and they complete the entire assignment. In this case, the first part of the assignment was done cooperatively but the second part was again parallel. 


\section{Example \#2: Psychology}

The second set of examples comes from the course on Psychology. There were seven groups (called Psych-A, Psych-B, etc.) in two sections of the course, ranging from three and six students per group. At least one student failed to show up in four of the groups, but all seven groups finished their projects.

Although the instructional designer felt that the project had been well scaffolded by asking the students to begin with brainstorming - thus in theory circumventing the immediate need to get organized - in only three of the seven groups was there anything resembling brainstorming and in one of those cases (Group Psych-C, below), the student was immediately undermined by a move to split the work:

\section{Group Psych-A:}

FIRST POST: "We are I feel a bit late to begin the brainstorm ... Anyway. I make some research about cultural influence on memory. We have to choose between cultural or social influences, and sorry but as we are late I have chosen by myself to look at cultural influences. But if you have done any research on the other then we can change but in order to start. Cultures bring up huge differences between people's perception of the world. As said on this site [url], we focus on different things according to how our culture influences us. As we have different perceptions of the world, we focus on different things, and we choose to remember or keep some information a person from another culture would not choose. In that sense, culture influences memory. Values from cultures do also differ. For Asian people for example, the self is more perceived as someone in a group whereas an American or western people is an independent individual separated from others. Memories for Asian's own desires and attitudes are less accessible than for a Western man. Asians think more according to social values and obligations, while Americans like to do as they wish.

RESPONSE: “Haha, I didn't know you had such close observation of Asian cultures and values. But precisely what you said was right. Culture/social is the background influence, they influence us to think about something more than the other. For Asians, our culture influences us to think about family more than ourselves (for the majority of people), so we tend to remember more things that happened in the family etc. Family events may be the ones that come to my mind before I think about teachers or school (just an example, which is not true, haha) whereas a Western person may think about things 'I' have to do before the things I have to do for my family members.”

\section{Group Psych-B}

FIRST POST: "Our group assignment is to "Think about how different cultures generate expectations for "boys" and "girls".' I was wondering if focusing on the different gender expectations in our own cultures and a second culture would be a good idea... For example I live in the United States so I'd examine expectations in this country and a separate country or tribe/community. Do any of us share the same country? If so maybe examine potential subgroups of that country for example religions, etc.?

RESPONSE: "I really like your idea on each of us focusing on our own country and another one. I live in Germany, and I have lived in Canada before, so would it be fine for you all if I look at those two? Another idea I had, was that we could look at different social institutions - such as school, workplace, marriage, etc. - and how they influence gender roles. What do you think about this?

\section{Group Psych-C}


FIRST POST: "Well... I guess I will just start then. I think that some cultural matter influence memory... like... for example, people remember things that they see, that doesn't usually happen. Like seeing a unicorn. You may always remember that (except for the fact that it can't happen). But it's crazy things like that people would remember. Maybe people might not remember bad things, like being abused as a child. Social factors also influence memory I think, because you always remember a good time with friends. And most people remember things like $9 / 11 \ldots$ where they were, what they were doing, etc. I don't really remember much about it, but I do remember watching the news about the tsunami's in Thailand. I guess this could be a start. haha

RESPONSE: “yeah! i think that's really good:) But i think we should divide up the roles and stuff first though. Like who's doing what and etc. and then later we can combine?"

In the remaining four groups, the students began with logistics, sometimes also sharing a resource. In only one case did this lead to further discussion of the content:

\section{Group Psych-D}

FIRST POST: "So I was thinking that we should get started and gather up resources and information for which cultural and/or social factors influence the memory. I'll be looking at some today, so we should get going and have these up by 12am EST. Let me know what people want to do for the presentation, etc.”

RESPONSE: I was thinking that since there are about three of us, we should each get a relevant source because we need about that many, as stated in the rubric. Then once we have reviewed everyone's info we can start working on the presentation for next week. Your timing seems good enough.

\section{Group Psych-E}

FIRST POST: "I was wondering where we wanted to start on this project, how we wanted to split up the work and exactly how we were going to go about this?”

RESPONSE: "I thought that we could maybe split the work, so that two people concentrate on social influences and the other two concentrate on cultural influence? What do you all think about it? I am happy to also do it differently :)

\section{Group Psych-F}

FIRST POST: "I'll found an article about social factors influencing memory.”

RESPONSE: "Hi, here are some good websites.”

\section{Group Psych-G}

FIRST POST: “And I was thinking maybe in our presentation we could include Bartlett and Allport \& Postman? I'm pretty sure their studies are linked closely with the topic :)”

RESPONSE: "Where can I find these studies?"

It should not be surprising that Group Psych-A and Group Psych-B had by far the greatest number of words per active participant--694 and 451 respectively--with Group Psych-D having the least--only 92.

More surprising, however, were the grades received by each group. Groups Psych-A, Psych-C, Psych-D, and Psych-F in Section 1 of the course were assigned numerical grades ranging from one to twenty points. 
Groups Psych-B, Psych-E, and Psych-G in Section 2 of the course were graded categorically (Excellent, Well done, etc.). In Section 1, Group Psych-C received the highest grade (20 out of 20) while Group Psych-A received the lowest (14). In Section 2, Group Psych-G received the highest grade (Excellent) and Group Psych-B the "lowest” (Well done).

In other words, skipping the brainstorming and getting organized quickly was more likely to lead to a high final grade than following the instructions and actually brainstorming.

\section{B. Types of interaction}

After each groups' initial discussion, there was little collaboration among the students: if a group could find a way to split work, that is what it did. In the Economics course, the design of the problem and the fact that the final submission took the form of a Word document facilitated this division of labor. Only one group of the five could be considered to have collaborated during the project. For the other groups, the interactions were entirely parallel, with even the final summative aspect almost always assigned to one student alone.

In the Psychology course, the students were required to create their final presentation using Google Presentations. While a shared document platform should have made it easier, and therefore more likely, for students to contribute to slides created by other students in their group and work collaboratively, this was seldom the case. In all seven groups, the students split the work by assigning a different piece to each group member. In four of the seven groups, the discussion forum was used to discuss logistics and the slides were authored individually. In the other three, the students posted some ideas about their slide content to the discussion forum but still authored their slides individually.

To look at these differences in greater detail, we focused on the highest and lowest rated groups in Section 1- Group Psych-A (score: 14) and Group Psych-C (score: 20).

As described above, Group Psych-A was the group that followed instructions and began with some brainstorming while Group Psych-C had the first poster's brainstorm undermined by a post about logistics. Although the average number of posts in the discussion forum per active participant in each group was not dissimilar (9 for Group Psych-A and 7 for Group Psych-C), the nature of the posts was quite different. Each post was coded for whether it primarily focused on content (including sharing resources) or organization/logistics. Group Psych-C continued the emphasis on logistics, with nine posts about organization/logistics, three posts about content/resources, and the rest apologies for missing deadlines or congratulations for work well done. Group Psych-A, in contrast, was more focused on content, with eight posts about content/resources, five about organization/logistics, and two congratulations at the end.

As noted above, the assignment was to research and report on the social and cultural factors that affect memory. By using the wiki-like nature of Google Presentations to track every addition and modification to each presentation sequentially over time, it was possible to chart the extent, and ways, in which the students interacted as they authored their final presentations. Figure 1 is a screenshot of students' interactions and revisions. Each revision can be viewed and compared (manually) to its previous version to see the evolution of students' alterations-a painstaking and time-consuming process that nevertheless illuminates each group's process. 


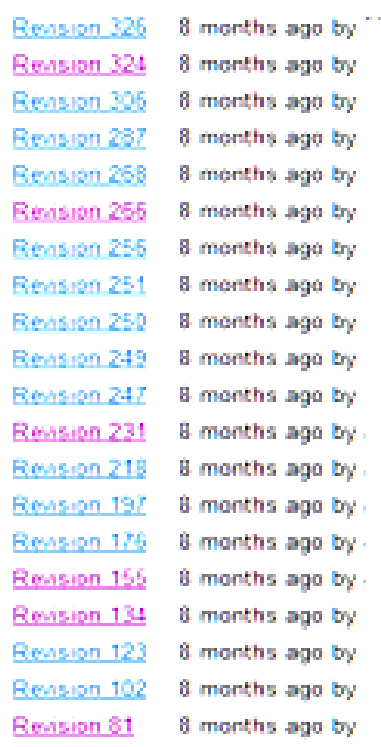

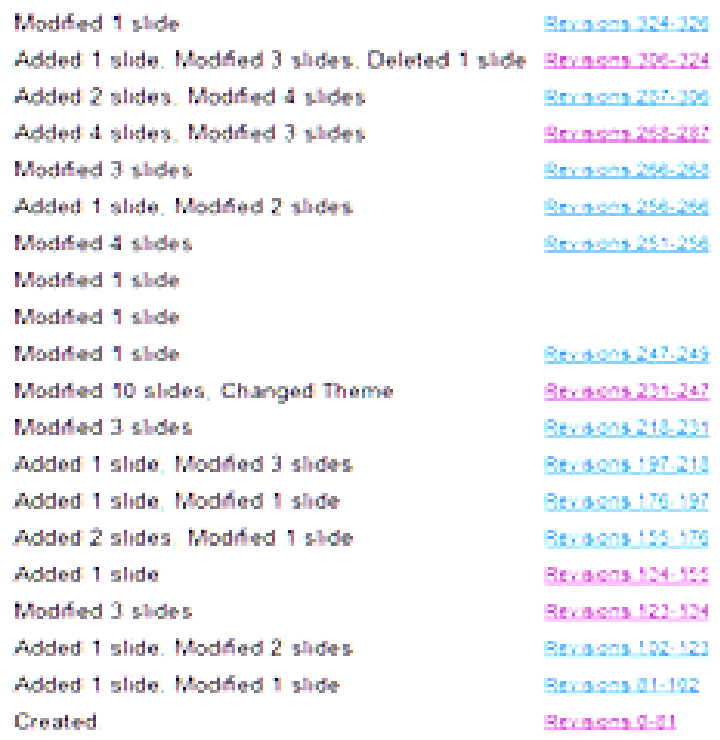

Figure 1: Screenshot from Google Presentations

When we compare the creation/revision process for the two groups, we see that they continued to interact very differently. For Group Psych-C, Student01 took the lead in framing the presentation by creating four topic slides. The group then split into pairs: Student01 and Student02 worked together on the Social slides while Student03 and Student04 worked on the Cultural slides. Each pair was an example of cooperative interaction, but the interaction between the pairs was parallel. The conclusion was somewhat collaborative, with contributions from one member from each pair. Overall, this group's work might be considered at best associative.

\begin{tabular}{|l|}
\hline Set up \\
\hline Social \\
\hline \hline Cultural \\
\hline
\end{tabular}

\begin{tabular}{|l|l|}
\hline GROUP C & ASSOCIATIVE \\
\hline Student01 & Creates title slide \\
\hline Student01 & Creates Cultural slide \\
\hline Student01 & Creates Social slide \\
\hline Student01 & Creates Conclusion slide \\
\hline Student02 & Adds to Conclusion slide \\
\hline Student01 & Creates Social subslide \\
\hline Student03 & Adds text to Cultural slide \\
\hline Student01 & Adds text to Social slide \\
\hline Student01 & Creates Social subslides \\
\hline Student01 & Adds text to Social subslides \\
\hline Student04 & Creates Cultural subslide \\
\hline Student04 & Adds text to Cultural subslide \\
\hline
\end{tabular}




\begin{tabular}{|l|l|} 
Student02 & Adds text to Social subslide \\
\hline Student04 & Creates Cultural subslides \\
\hline Student04 & Adds text to Cultural subslides \\
\hline Student02 & Creates Social subslide \\
\hline Student02 & Adds text to Social subslide \\
\hline Student02 & Adds to Conclusion \\
\hline Student04 & Edits and organizes \\
\hline Student02 & Adds to Social subslides \\
\hline Student02 & Edits and organizes \\
\hline
\end{tabular}

Figure 2: Group Psych-C, Associative

Group Psych-A, on the other hand, was an example of a truly collaborative interaction, with each member contributing to the other member's sections. One group member again framed the presentation by created three topic slides-but then disappeared. The remaining four group members contributed to both the Cultural and Social slides. Student03 and Student04 worked on the introduction and Student04 edited the final presentation—all in all, a fairly collaborative process.

\begin{tabular}{|l|l|}
\hline GROUP A & COLLABORATIVE \\
\hline Student01 & Creates title slide \\
\hline Student01 & Creates Social slide \\
\hline Student01 & Creates Cultural slide \\
\hline Student02 & Adds text to Social slide \\
\hline Student02 & Adds text to Cultural slide \\
\hline Student03 & Adds Intro slide \\
\hline Student03 & Adds text to Intro slide \\
\hline Student03 & Creates Cultural subslides \\
\hline Student03 & Creates Social subslides \\
\hline Student03 & Adds text to Social subslides \\
\hline Student04 & Adds text to Intro slide \\
\hline Student04 & Adds text to Social slides \\
\hline Student04 & Adds text to Cultural slides \\
\hline Student05 & Adds text to Cultural slides \\
\hline Student05 & Adds text to Social slides \\
\hline Student02 & Creates Cultural subslides \\
\hline Student02 & Adds to Cultural subslides \\
\hline Student04 & Edits and organizes \\
\hline
\end{tabular}

Figure 3: Group Psych-A, Collaborative 
Yet it was Group Psych-C that had the higher total number of points, as well as higher scores on the three items in the scoring rubric_-knowledge/comprehension, evidence of critical thinking, and organization. Table 1 shows the comparative points:

\begin{tabular}{|c|c|c|}
\hline & Group Psych-A & Group Psych-C \\
\hline Knowledge/comprehension & 6 & 8 \\
\hline Evidence of critical thinking & 5 & 8 \\
\hline Organization & 3 & 4 \\
\hline Total & 14 & 20 \\
\hline
\end{tabular}

Table 1: Grades for Groups Psych-A and Psych-C

\section{IMPLICATIONS FOR SUCCESSFUL ONLINE GROUP WORK}

Although group work in online classrooms operates with different constraints and affordances than group work in face-to-face classrooms, they have some characteristics in common. In a study of peer interaction in face-to-face classrooms, Hogan, Nastasi, and Pressley [18] found that students often spend more time working out how to complete a task than in learning from it, that participation varies from member to member, and that students often do not try to clarify their own or their peers' understandings. Those findings seem to apply equally to the online group work described here. As the examples show, almost all the "talk" in these groups was about organizing the work, not about the work itself. Thus the students almost never engaged in what Wegerif, Mercer, and Dawes [14, p. 496] call "exploratory" talk, where a group critically but constructively engages with each other's ideas about the problem itself. They instead opted for a parallel style of interaction.

On the other hand, in the online environment the cooperative style for getting organized cannot be too cooperative or projects do not get completed. The initial post is as important as the response, with the most successful groups being those where one member takes charge and the others follow along. In faceto-face group work, this person is often accused of "bossiness," but in the online environment this type of leadership may be crucial for success. However, one common complaint about face-to-face group workthat some students do all the work while others are "free-loaders"-clearly applies online as well.

This leads to a number of suggestions for designing group projects that are truly collaborative. First, instructional designers must create projects that incorporate the two key elements of what Johnson and Johnson [20] have called "positive interdependence”: (1) Each group member's efforts must be required and indispensable for group success and (2) each group member must have a unique contribution to make. Neither of these elements was incorporated into the design of either project in the present study. As a result, Mercer's second condition for "good talk" - that the activity is designed to encourage collaboration-was missing.

Second, collaboration can be facilitated by the use of collaborative spaces, as the Psychology groups did with Google Presentations. Although this did not necessarily lead to collaboration, it did make it easier.

Third, and perhaps most important, students need very clear instructions as to what collaboration should look like. There was no suggestion that any of the students in these groups felt that their collaborative style did not meet expectations. In addition, they were reluctant to correct each other, almost always accepting each other's contributions without comment. Students need to know what "good talk" and cooperative interaction look like in the online environment.

This leads directly to the issue of how group projects are assessed. For the Psychology course, whether or not the students followed the instructions to brainstorm, how much they interacted with each other, and how much they actually collaborated were not reflected in the final grades. Since it may well have been 
that some projects were more accomplished than others, this suggests that grades for group projects should not be based solely on the final product but should incorporate success with the research and writing process. For example, in asynchronous online courses teachers often give a separate grade for engagement in order to reward students who participate fully in the course. Similarly, in face-to-face classes teachers often grade the group process. Grades for online group work should take the process aspect into consideration as well.

Group projects in online courses have the potential for engaging students in collaborative work, not only to learn new content and concepts but to prepare them for future work. However, group projects are still a work in progress in terms of how best to structure, facilitate, and assess results. This research focused on the design of projects and students' interactions with each other as they completed group assignments, but there are additional areas in need of research, including best ways to create productive groups (strong students with weaker students, strong students together, etc.), ideal group size, and the degree and type of teacher intervention. There is much work to be done.

\section{ACKNOWLEDGMENTS}

With many thanks to Drs. Seungoh Paek and Devayani Tirthali who provided invaluable assistance with the data analysis when they were graduate students in the Program in Computers, Communication, Technology, and Education at Teachers College/Columbia University.

\section{ABOUT THE AUTHOR}

Dr. Susan Lowes is Director of Research and Evaluation at the Institute for Learning Technologies (http:/www.ilt.columbia.edu) and Adjunct Professor in the Program in Computers, Communication, Technology, and Education at Teachers College, Columbia University, where she teaches courses on methodologies for researching technology in education and on online schools and schooling at the K-12 level. She is particularly interested in online learning and has researched and published on online professional development initiatives for teachers and administrators, as well as on courses and programs for students.

\section{REFERENCES}

1. International Association for K-12 Online Learning (iNACOL). National Standards for Quality Online Courses, ver. 2. Vienna, VA: iNACOL, 2011.

2. International Association for K-12 Online Learning (iNACOL). National Standards for Quality Online Teaching, ver. 2. Vienna, VA: iNACOL, 2011.

3. Jarvenpaa, S.L. \& Leidner, D.E. Communication and trust in global virtual teams. Organizational Science 10(6): 791-815 (1999).

4. $\mathbf{R W}^{3}$ Culture Wizard. Virtual Teams Survey Report: The Challenges of Working in Virtual Team. New York: RW ${ }^{3}$ Culture Wizard, 2010.

5. Anderson, A.H., McEwan, R., Bal, J. \& Carletta, J. Virtual team meetings: An analysis of communication and context. Computers in Human Behavior 23(5): 2558-2580 (2007).

6. Ebrahim, N.A., Ahmed, S., \& Taha, Z. Virtual R\&D teams in small and medium enterprises: A literature review. Scientific Research and Essays 4(13): 1575-1590 (2009). 
7. Carabajal, K., LaPointe, D., \& Gunawardena, C.N. Group development in online learning communities. In M.G. Moore \& W.G. Anderson (Eds.), Handbook of Distance Education (pp. 217234). Mahwah, NJ: Lawrence Erlbaum Associates, 2003.

8. Ikpeze, C. Small group collaboration in peer-led electronic discourse: An analysis of group dynamics and interactions involving preservice and inservice teachers. Journal of Technology and Teacher Education, 15(3): 383-407 (2007).

9. Roberts, T. S. \& McInnerney, J. M. Seven problems of online group learning (and their solutions). Educational Technology and Society 10(4): 257-268 (2007).

10. Goggins, S., Galyen, K., \& Laffey, J. Network Analysis of Trace Data for the Support of Group Work: Activity Patterns in a Completely Online Course. Proceedings from ACM Group 2010, Sanibel Island, FL, 2010.

11. Mercer, $\mathbf{N}$. The quality of talk in children's collaborative activity in the classroom. Learning and Interaction 6(4): 359-377 (1996).

12. Mercer, $\mathbf{N}$. Sociocultural discourse analysis: Analysing classroom talk as a social mode of thinking. Journal of Applied Linguistics 1(2): 137-168 (2004).

13. Mercer, $\mathbf{N}$. The seeds of time: Why classroom dialogue needs a temporal analysis. Journal of the Learning Science 17(1): 33-59 (2008).

14. Mercer, N., Wegerif, R. \& Dawes, L. Children's talk and the development of reasoning in the classroom. British Educational Research Journal 25(1): 95-111 (1999).

15. Barron, B. Achieving coordination in collaborative problem-solving groups. The Journal of the Learning Sciences 9(4): 403-436 (2000).

16. Barron, B. When smart groups fail. The Journal of the Learning Sciences 12(3): 307-359 (2003).

17. Forman, E. A., \& Cazden, C. B. Exploring Vygotskian perspectives in education: The cognitive value of peer interaction. In J. V. Wertsch (Ed.), Culture, communication, and cognition: Vygotskian perspectives (pp. 323-347). New York: Cambridge University Press, 1985.

18. Hogan, K., Nastasi, B.K., \& Pressley, M. Discourse patterns and collaborative scientific reasoning in peer and teacher-guided discussions. Cognition and Instruction 17(4): 379-432 (1999).

19. Kim, I-H, Anderson, R.C., Nguyen-Jahiel, K., \& Archodidou, A. Discourse patterns during children's collaborative online discussions. The Journal of the Learning Sciences 16(3): 333-370 (2007).

20. Johnson, D.W. \& Johnson, R.T. An overview of cooperative learning. In J. Thousand, A. Villa and A. Nevin (Eds,), Creativity and Collaborative Learning. Baltimore: Brookes Press, 1994. 